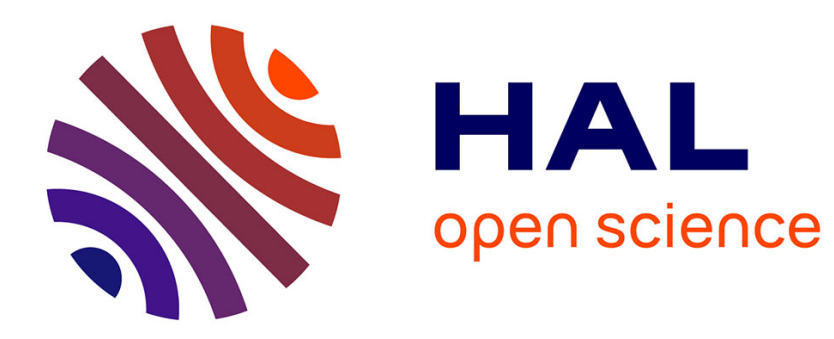

\title{
PARAMAGNETIC O-2 DEFECTS IN APATITES
}

\author{
J. Dugas, C. Rey
}

\section{To cite this version:}

J. Dugas, C. Rey. PARAMAGNETIC O-2 DEFECTS IN APATITES. Journal de Physique Colloques, 1976, 37 (C7), pp.C7-449-C7-451. 10.1051/jphyscol:19767100 . jpa-00216821

\section{HAL Id: jpa-00216821 https://hal.science/jpa-00216821}

Submitted on 1 Jan 1976

HAL is a multi-disciplinary open access archive for the deposit and dissemination of scientific research documents, whether they are published or not. The documents may come from teaching and research institutions in France or abroad, or from public or private research centers.
L'archive ouverte pluridisciplinaire HAL, est destinée au dépôt et à la diffusion de documents scientifiques de niveau recherche, publiés ou non, émanant des établissements d'enseignement et de recherche français ou étrangers, des laboratoires publics ou privés. 


\title{
PARAMAGNETIC $O_{2}^{-}$DEFECTS IN APATITES
}

\author{
J. DUGAS (*) \\ Laboratoire de Physique des Solides, Université Paul-Sabatier, \\ 31077 Toulouse Cedex, France \\ C. REY \\ Laboratoire de Physico-Chimie des Solides et des Hautes Températures, \\ Ecole Nationale Supérieure de Chimie, 38, rue des 36 ponts, Toulouse, France
}

\begin{abstract}
Résumé. - La R. P. E. permet la mise en évidence et la caractérisation de l'ion superoxyde $\mathrm{O}_{2}^{-}$ dans les tunnels de différentes apatites oxygénées. On compare leur situation à celle que ces ions occupent dans les halogénures alcalins.
\end{abstract}

\begin{abstract}
The superoxide $\mathrm{O}_{2}^{-}$ion is studied by E. S. R. in various oxygenated apatites. It allows to state its position and its orientation in the channel of the apatites. One compares these results with those obtained in alkali-halides.
\end{abstract}

Before presenting some results about $\mathrm{O}_{2}^{-}$defects in apatite structures it is important to define what is an apatite.

The simplest and chemically stablest apatite is the fluoro-phosphate calcium apatite, the formula of which is

$$
\mathrm{Ca}_{5}\left(\mathrm{PO}_{4}\right)_{3} \mathrm{~F} \text {. }
$$

Its crystal structure is hexagonal. Projecting it on the (00.1) plane one obtains the figure 1 [1]. A first

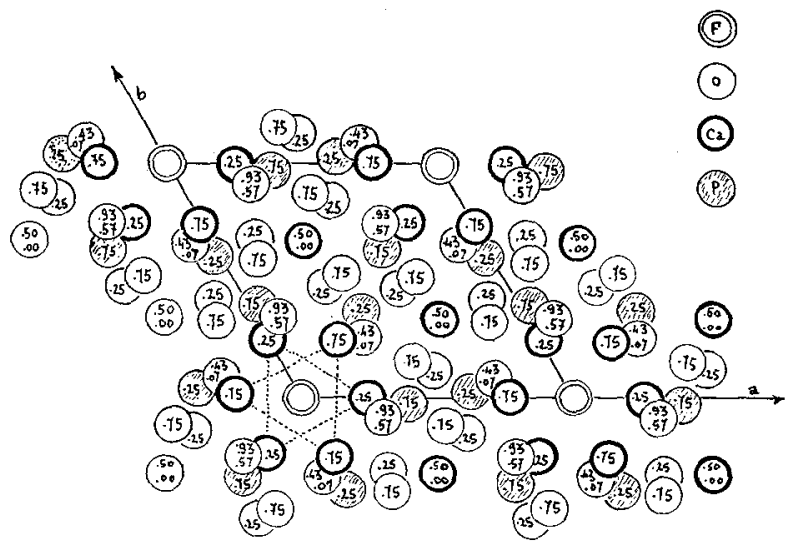

FIG. 1. - Projection of the apatite structure on the (00.1) plane.

peculiarity is the existence of two kinds of sites for the calcium ions. The 0.0 and 0.5 ones are in a trigonal neighbourhood while the others have no symmetry element.

(*) Present address : Département de Physique, Université Mohammed V, Faculté des Sciences - Rabat (Morocco).
One can substitute some of them by transition or rare earth ions which award interesting fluorescence properties to the apatites which are commonly used as inner coating in the strip lighting. It provides at the same time laser crystals.

Except in its crystal parameters, this structure is not appreciably modified if all the fluorines are substituted by chlorine, bromine, hydroxyl, carbonate ions. In the same way, all the calciums may give up their place to strontium or barium ions, while arsenate or vanadate ions may play the same part than the phosphates do.

For us, it is important to notice that the anions such as halogens, hydroxyls,... always stay along linear channels which run parallel to the $c$-axis of the hexagonal structure. According to their size the sites they occupy in the channel are different. Fluorines may stay at $c / 4$ and $3 c / 4$, in the middle of alkaline earth triangles; bigger chlorines have not enough room and must remain near $c$. 2 .

When alkaline earth nitrates are dropped in solutions of diammonium hydrogen phosphate (or arsenate) containing hydrogen peroxide, one obtains at $80^{\circ} \mathrm{C}$ apatite precipitates the channel of which contains $\mathrm{OH}^{-}, \mathrm{O}_{2}^{2-}, \mathrm{O}_{2}^{-}$ions [2].

The last ones are paramagnetic and E. S. R. experiments provide informations about their behaviour in the lattice.

The results we present here, have been obtained on phosphate and arsenate apatites with calcium, strontium and barium cations. Hitherto we have not been able to work out sufficiently large single crystals, however, as we go to see now, E. S. R. results permit 
TABLE I

$$
\begin{gathered}
\text { Oxygenated apatite } \\
\text { compounds } \\
\overline{g_{z}} \\
g_{x}=g_{y}
\end{gathered}
$$

Phosphate
Strontium
2.081
2.000

to put forward a proposal for the situation and the orientation of the $\mathrm{O}_{2}^{-}$ion in the channel.

All the measurements were achieved with an X-band homodyne spectrometer at liquid nitrogen temperature where the spectra were spectacularly enhanced.

With such powdered samples, all these averaged spectra are characteristic of an anisotropic $g$-factor with two well resolved components. In the calcium arsenate apatite alone it were more difficult to determine a correct $g_{z}$ value. In the table $I$ are gathered the different $g$ components for all the studied apatites.

These results have to be compared with those which have already been obtained by Kanzig et al. [3] with the same superoxide ions in alkali halides. Typically for $\mathrm{KCl}, g$-components are :

$$
g_{x}=1.951, \quad g_{y}=1.955, \quad g_{z}=2.436
$$

and thus the $g$-shifts appear being greater than in our case. Zeller and Kanzig [4] have related these $g$-shifts to the crystal field effect. Indeed in superoxide $\mathrm{O}_{2}^{-}$ions, the unpaired electron is in an orbitally degenerated ${ }^{2} \pi_{g}$ level. In a crystal, if the neighbourhood has not the same axial symmetry, this degeneracy is split. Taking in account, at the same time, the spinorbit coupling interaction $\lambda L . S$ and this crystal field splitting $\Delta$ one obtains at first order :

$$
\begin{aligned}
& g_{x}=g_{y}=g_{e} \cos x \\
& g_{z}=g_{e}+2 \sin x
\end{aligned}
$$

where such is $x$ that $\tan x=\lambda / \Delta$.

Then, it is found that the greater is the crystal field effect the weaker are the $g$-shifts.

At the light of these calculations what may be the interpretation of our results?

First, the molecular axis of the $\mathrm{O}_{2}^{-}$ion cannot lie along the channel axis, otherwise the molecular symmetry would not be perturbed, the orbital degeneracy would not be split and the $g$-shifts would be much more important.

\begin{tabular}{|c|c|c|c|}
\hline Barium & Calcium & $\begin{array}{c}\text { Arsenate } \\
\text { Strontium } \\
\end{array}$ & Barium \\
\hline 2.147 & 2.06 & 2.090 & 2.158 \\
\hline 1.998 & 2.001 & 2.001 & 1.999 \\
\hline
\end{tabular}

Then, what is the position of $\mathrm{O}_{2}^{-}$in the channel ? If its center stays, as the fluorines do, at $c / 4$ and $3 c / 4$ in middle of calcium (or $\mathrm{Sr}, \mathrm{Ba}$ ) triangle, the surroundings would tend to make the molecular axis parallel to the channel one. It may be not the case.
Another, more interesting possibility consists to put its center at $c / 2$. Then it stays in an octaedron of alkaline-earth ions as it does in alkali-halides where the octaedron is formed with alkaline ions. Proceeding on this comparison, from crystal parameters we are able to compute the dimensions of these octaedrons in the apatites. One observes first that they are slightly streched along the $c$ axis except for the calcium arsenate apatite in which it is slightly flattened. This distortion may be measured by the ratio $p$ of the distances between two alkaline earth ions lying in the same $(a, b)$ plane and two staying at two different levels along $c$. The table II gives these ratios. One observes that they regularly decrease from calcium to barium apatites. Furthermore the diagonal lengths $l$ which are also given in table II, are approximatively the same than those of the alkaline octaedrons in the alkali halides $(6.29 \AA$ in $\mathrm{KCl})$, but the $2^{+}$charges of the alkaline earth ions increase, as observed, the crystal field effect.

Now we may suppose that the orientation in the octaedron is the same as in alkali halides, that is to say, that the $\mathrm{O}_{2}^{-}$ions are along medians of alkaline earth squares with their $\pi$ lobes towards each of these ions. This situation is represented in figures $2 a$

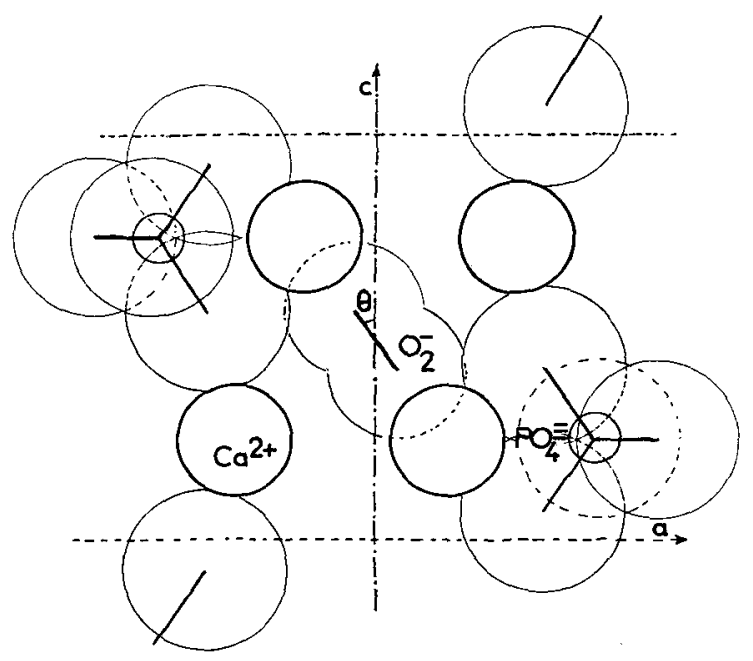

FIG. 2a. - Projection of the channel neighbour ions on the $(a, c)$ plane in the case of the calcium phosphate apatite.

TABLe II

Oxygenated apatite compounds

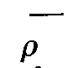

$l(\AA)$

$\begin{array}{cc}\text { Calcium } & \text { Phosphate } \\ \overline{-} & \text { Strontium } \\ 0 . \overline{982} & 0 . \overline{967} \\ 5.85 & 6.11\end{array}$

Barium
0.955
6.41

Arsenate

Strontium

$\begin{array}{ll}\overline{0.975} & 0 . \overline{966} \\ 6.26 & 6.55\end{array}$


and $2 b$ which are the projections of the channel neighbourhood either on the $(a, c)$ plane or on the plane containing the $c$-axis and perpendicular to the $a$-direction. Only the ions near these planes have been drawn.

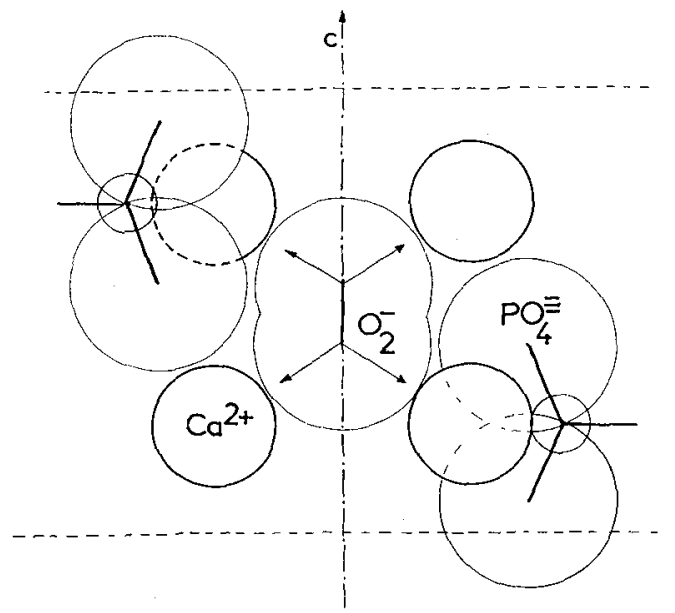

Fig. 2b. - Projection of the channel neighbour ions on the plane containing $c$ and perpendicular to the $a$ axis.

Another possibility would be to put, in the same square, the molecular axis perpendicular to the channel axis. However in this situation, the $\pi$ lobes would be forwards the negative charges of oxygens belonging to phosphate or arsenate ions. Thus such orientation seems unlikely except, perhaps, in the case of the calcium arsenate apatite where the slight flattening of the octaedron might promote it and that would not be at variance with the experimental result.

In our hypothesis for the general case, the superoxide ion axis is slanted by an angle $\theta$ on the $c$-axis. We represented in figure 3 the relative variation of $\Delta$ (derived from the $g_{z}$ shifts) versus the tangent of $\theta$.

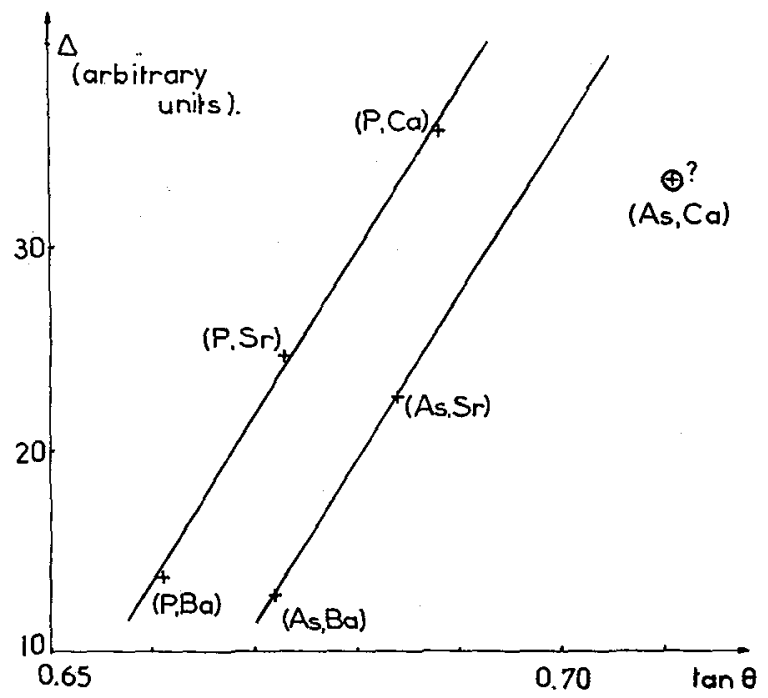

Fig. 3. - Variation of the crystal field splitting versus the tangent of the angle $\theta$ between the $\mathrm{O}_{2}^{-}$molecular and the channel axes.

Except for the calcium arsenate apatite for which we saw $\mathrm{O}_{2}^{-}$presents a particular behaviour, a linear variation is observed with the same slope for phosphate and arsenate apatites. We see here that the more stretched is the host octaedron the weaker is the crystal field effect, but weaker is the angle $\theta$. So it appears that the farther neighbourhood with its axial symmetry plays an important part in the rhombic crystal field undergone by the superoxide ion.

To conclude, after these observations and their interpretations, we want point out that it is possible to obtain essentially calcium phosphate apatites with very large concentrations of such magnetic dipoles. They may stay then in neighbour sites along the channel and form linear chains. Magnetic measurements at very low temperature are at the present time in progress.

\section{References}

[1] KAy, M. I., Young, R. A., Posner, A. S., Nature 208 (1964) 1050

[2] ReY, C., Thèse de $3^{e}$ cycle Toulouse, 1973.
[3] Kanzig, W., Cohen, M. H., Phys. Rev. Lett. 3 (1959) 509

[4] Zeller, H. R., Kanzig, W., Helv. Phys. Acta 40 (1967) 845.

\section{DISCUSSION}

J. ARENDS. - To produce your $\mathrm{O}_{2}^{-}$ions you must have heated your specimen for a long time at high temperature this might change the stoichiometry considerably. In fact you are most likely not dealing with a regular apatite structure.
J. DugAs and C. REY. $-\mathrm{O}_{2}^{-}$ions are introduced in the structure during the precipitation of apatites from solutions at about $80^{\circ} \mathrm{C}$.

The samples were never heated before experiments. 